\title{
Desigualdade social em questão: entrevista com Mário Theodoro (IPEA)
}

O pesquisador Mário Theodoro hoje pertencente à Diretoria de Estudos e Relações Econômicas e Políticas Internacionais do IPEA, tem livros e trabalhos publicados sobre o tema do trabalho e do desenvolvimento no Brasil. No IPEA, essa importante instituição governamental que produz indicadores sociais e dados de referência para a pesquisa no país, realiza estudos e o acompanhamento das políticas governamentais na área internacional, e organiza toda a cooperação com organismos internacionais, além da coordenação da Capacitação e Formação, o que inclui um Mestrado em Desenvolvimento e Políticas Públicas. Sua área de concentração é Mercado de Trabalho e Desenvolvimento. Segundo o pesquisador, o estudo da questão do desenvolvimento, ou melhor, sua busca incessante, o levou à questão inversa: o subdesenvolvimento, as raízes do atraso, os fatores históricos que determinaram e determinam o arranjo institucional e social que vige no Brasil. Em Pauta procurou neste número focar o debate sobre a desigualdade, pelo que consideramos fundamental escutar as opiniões de um intelectual e pesquisador que está no olho do furacão, considerando seu lugar estratégico: uma instituição como o IPEA. Com a palavra, Mário Theodoro.

\section{(Entrevista realizada por Elaine Rossetti Behring)}

Em Pauta: Como você analisa as raízes históricas da desigualdade brasileira e sua relação com a formação capitalista à brasileira, país que não viveu uma via clássica de revolução burguesa e modernização capitalista?

Mário Theodoro: A desigualdade brasileira tem seguramente um componente histórico ancorado no nosso passado escravista. A própria ideia de trabalho esteve durante muito tempo associada ao elemento escravo. O trabalho como exercício humano, como uma atividade produtiva, era, pois, desvalorizado, coisa de negro, escravo, ou de pobre. Nosso capitalismo se forjou a partir de uma dada inserção do Brasil no sistema econômico internacional como produtor de bens primários (paubrasil, cana-de-açúcar, ouro, café...). O interesse econômico, a exploração eco- 
nômica, estava na raiz da própria existência do Brasil. Antes do social, veio o econômico. Isso nos deixou marcas profundas. O escravismo mal resolvido e a concomitante substituição do trabalho negro pelo imigrante nos legaram um excedente estrutural de força de trabalho. $\mathrm{O}$ assalariamento organizado a partir da década de 1930 cumpriu apenas uma parte de sua missão histórica: estabilizou a mão de obra para o capital. Mas, de outro lado, não se universalizou. Daí a grande incidência da informalidade, que responde por cerca de metade das relações de trabalho no Brasil. Nosso capitalismo, que alguns chamam de periférico e outros, de tardio, ainda se depara com a questão da inserção internacional como grande produtor de bens primários, agora chamados de commodities. O debate sobre o futuro do Brasil guarda ainda relação direta com o debate sobre o desenvolvimento lançado por Furtado: cresceremos sendo a grande fazenda do mundo, o grande supridor de alimentos e outros bens primários ou fortalecemos nosso mercado interno, nossa produção industrial, nossa ciência e tecnologia para brigar com os grandes? Essa disjuntiva nos assola e nos assolará nos próximos anos.

Em Pauta: De um ponto de vista conceitual, que categorias você considera fundamentais para uma reflexão sobre o tema da desigualdade?

Mário Theodoro: No Brasil, a desigualdade tem uma conformação particularmente ligada ao passado de escravidão. São trezentos e cinquenta anos sob o regime escravista, ao fim do que a sociedade se impregnara do racismo e de seus dois principais desdobramentos: o preconceito e a discriminação racial. Mas reputo o racismo como a categoria central para o entendimento da desigualdade no Brasil. O racismo naturaliza a desigualdade, fazendo com que situações de iniquidade gritantes continuem sendo percebidas como normais, comezinhas. O racismo ordena a sociedade, estabelece uma dada hierarquia que distingue os indivíduos e seleciona oportunidades, cristalizando a desigualdade. Não nos vemos como iguais e essa é a nossa maior tragédia. É evidente que existem pobres brancos, bem como negros ricos. Mas os negros, em sua grande maioria, são os mais pobres, bem como os menos escolarizados, os mais afeitos à situação de desemprego, à violência policial etc.

Em Pauta: Existem grandes controvérsias sobre a mensuração da desigualdade, a exemplo do que revelam os dados do PNUD e as reações oficiais à sua divulgação, e interpretações a partir de diferentes indicadores, como o Coeficiente de Gini, que não revelaria a desigualdade do acesso à riqueza, mas sim à renda. Como você vê essas controvérsias e, na sua opinião, quais seriam os indicadores mais consistentes para pensar a desigualdade no Brasil?

Mário Theodoro: De fato, temos limitações importantes com respeito aos dados utilizados para a mensuração da desigualdade. O que temos de melhor é a PNAD (Pesquisa Nacional de Amostras de Domicílios), do IBGE, que trata basicamente dos rendimentos do trabalho. Toda informação sobre a chamada distribuição funcional da riqueza - da famosa distribuição entre salários, juros e lucros —, que só pode ser retirada das contas nacionais, tem problemas de manipulação, tanto pelo seu grau de agregação como por sua periodicidade. Assim, sobra-nos a PNAD, que 
nada diz sobre a distribuição funcional - ainda que, no caso brasileiro, onde a desigualdade entre os assalariados (aqui entendidos como sendo todos aqueles que vivem do trabalho, formal ou informalmente) também é gritante, esse dado também seja importante. De todo modo, o que dá para falar a partir do nosso Gini da PNAD é que a renda entre os que vivem do trabalho está melhor distribuída. Mas nada se pode falar do papel crescente dos juros e lucros na composição do nosso PIB. Do ponto de vista da economia política, temos uma limitação de dados que nos impede uma análise mais profunda da distribuição da renda.

Em Pauta: Existem controvérsias também sobre o impacto das políticas sociais no país, especialmente sobre se o Coeficiente de Gini teria baixado em função da transferência de renda com condicionalidades, ou se as políticas universais articuladas ao aumento do salário mínimo teriam mais impacto. Como você analisa esse debate?

Mário Theodoro: Penso que esse seja um debate recorrente. Reproduz um pouco a controvérsia da focalização versus universalização que travamos na virada da última década. Penso que, numa sociedade como a brasileira, com profundas desigualdades, temos lugar para os dois tipos de intervenção. Os programas de transferência de renda têm lá sua importância, sobretudo tendo em vista nosso histórico e estrutural excedente de mão de obra que, combinado com a desigualdade, coloca uma horda de miseráveis nas ruas das grandes cidades a vender serviços a qualquer preço (lavar ou guardar carro, engraxar sapatos, vender bugigangas etc.). Penso que a renda mínima dá um grau de escolha (ainda que muito restrito) ao pobre. Não vai trabalhar por qualquer trocado - pelo menos não em determinadas horas e/ou condições insalubres. Isso é positivo. Mas esses programas não podem vir sozinhos. Isso não funciona. Ou melhor, funciona perenizando a pobreza, a miséria e a desigualdade. Cria cidadãos de segunda categoria, naturaliza a iniquidade... um problemão. É imprescindível a montagem de um sistema de proteção social nos moldes clássicos: universalista, associado a uma política de valorização salarial, bem como a um regime fiscal progressivo. E tudo isso vinculado a um crescimento econômico ancorado na distribuição da renda. Esse é o único caminho conhecido para findar com a miséria, a pobreza e a desigualdade. Ah, sim, e no campo, reforma agrária, bem entendido. Vejo assim que o melhor dos mundos é a associação dos dois tipos de programa.

Em Pauta: Fale-nos um pouco sobre outros recortes que considera importantes na análise da desigualdade brasileira, a exemplo de gênero e raça.

Mário Theodoro: Penso que haja ainda alguns outros recortes a serem considerados. O primeiro é o de região. A questão regional não foi devidamente resolvida. O Nordeste continua sangrando, com vastas hostes de pobres. O Norte tem nas atividades predatórias seu maior problema. O Centro-Oeste veste a carapuça do agronegócio como grande solução econômica, o que me parece um equívoco, dadas as consequências sociais e ambientais desse tipo de empreendimento. Mas o mais problemático é a concentração econômica em poucos estados, o que desequilibra o país do ponto de vista social e político. Isso já foi muito estudado. Furtado alertou 
sobre isso. Chico de Oliveira, Tânia Bacelar, enfim, temos muita coisa escrita. E finalmente a clivagem de classe não pode ser descartada. Ao contrário, deve ser reconstruída, tendo em vista nossa trajetória histórica, nossas idiossincrasias e nossas construções sociais. Mas é na categoria classe social que reside a perspectiva da transformação social e seus limites. É fundamental para entender nossas possibilidades de trajetória futura.

Em Pauta: Já existem alguns dados parciais divulgados sobre o Censo 2010. Qual a sua percepção do país que este novo censo revela? Quais questões metodológicas e tecnológicas você destacaria neste novo Censo e que terão impacto neste Brasil mais uma vez revelado?

Mário Theodoro: De fato, ainda não há muita informação. É muito cedo. O que saiu em termos de dados é pouco, e muito agregado. Vamos esperar para ver o que vem. De todo o modo, a maior expectativa é sobre como virá o dado sobre raça/ etnia em face da mudança metodológica: até o último censo, as questões sobre raça/etnia faziam parte do questionário completo, que era aplicado em apenas 10\% do universo. Agora é para todos. Vamos ver.

Em Pauta: O chamado novo-desenvolvimentismo tem produzido impactos significativos na desigualdade brasileira? E, na sua opinião, existe efetivamente um novo desenvolvimentismo?

Mário Theodoro: Eu vejo esse novo-desenvolvimentismo mais como o resgate do velho desenvolvimentismo incorporando algumas questões, como a do meio ambiente e a da inclusão social. Penso que a raiz é a mesma. Minha preocupação maior é com o que vamos fazer com a ideia do desenvolvimento. Utilizá-la efetivamente como um objetivo nacional a ser perseguido pelo Estado e pela sociedade ou, como antes, servirmo-nos dela como uma espécie de ideologia do porvir que aceita e convive com todo tipo de mazela social. O desenvolvimento no Brasil, contraditoriamente e por muito tempo, serviu de bandeira do amanhã para que não pensássemos nos problemas de hoje. A ideia do "país do futuro" aplacava nossas vicissitudes e nosso complexo de vira-latas. O discurso político nacional se ancorava — e se ainda se ancora — na ideia do desenvolvimento. Não como fator de mudança social, mas como fator de inação, de inércia. Implicitamente há a ideia do "calma, chegaremos lá". Não necessitamos de reformas e a fome um dia acabará no país do futuro. No país do futuro, o desenvolvimento é inexorável. Mas o futuro está no horizonte, inatingível. A falta de visão do futuro como sendo efetivamente o resultado do que faremos a partir de agora é a chave da ideologia do desenvolvimento. Isso realmente me preocupa. 